\title{
Optimization of Fermentation Process Parameters for Ginsenoside Re Bioconversion by Plackett-Burman and Box-Benhnken Design
}

\author{
Xiuhong Wu*, Lina Zhang, Ailin Sui, Boqu Qu, Shaoyan Wang \\ Department of Chemical and Engineering, University of Science and Technology of Liaoning, Anshan, Liaoning, 114051, \\ China
}

\begin{abstract}
In this work, Plackett-Burman (PB) and Box-Behnken (BB) experiment design were used to investigate the medium components of fermentation forth of ginsenoside Re bioconversion to ginsenoside Rh1. Firstly, nine variables including cultivation time, temperature, $\mathrm{pH}$, reactant concentration, inoculum's size, peptone, $\mathrm{MgSO}_{4} \cdot 7 \mathrm{H}_{2} \mathrm{O}$, $\mathrm{K}_{2} \mathrm{HPO}_{4}$ and $\mathrm{NaNO}_{3}$ were screened. The most important effective factors were estimated according to the statistical regression. Subsequently, the steepest ascent experiment was used to approach the optimum response range for each effective factor. Then Box-Benhnken Design (BBD) was finally used to analyze the response surface of the screened factors for further optimization. The optimized conditions for the influential factors were: ginsenoside Re $1.0 \mathrm{~g} / \mathrm{L}, \mathrm{pH}$ 4.5 and 7 days. The bioconversion of ginsenoside Re to Rh1 could reach up to $51.76 \%$.
\end{abstract}

\section{Introduction}

The history of people utilized natural product has been gone through nearly for thousands of years, especially in Asia. For a few decades, people concerned increasingly the definite component of the natural product as it has been reported that these main components have the properties of neuroprotection, cardiovascular system protection, anti-oxidant, anti-diabetic, anti-cancer et al. [1-4]. Nowadays, minor components such as taxol, ginsenoside $\mathrm{Rg} 3, \mathrm{Rh} 1$ are gaining increasingly attention as they have more physiological activities [5-8]. Bioconversion catalyzed by either microorganism or isolated enzyme nowadays has become an attracted approach to produce pharmaceuticals, especially such kind of minor component [9-13]. Though biotransformation has the characteristic of the mild reaction condition, relative higher selectivity, the target transformation ratio was still in a relative lower level due to the very complex condition of bio-reaction system. The common methods "one factor at a time" would not account for the interactions between the factors. In recent years, the statistical methods served as an effective way to screen for the important factors among many variables was the use of the Plackett-Burman design. The key is forming various combinations of the factors with various combinations of the factors with various amounts and could limit the factors for optimization. Subsequently, the actual values of these factor could achieve by BoxBehnke design which could understanding the interactions among various process parameters [14-18].
In our previous work, $\mathrm{PB}$ and $\mathrm{BBD}$ methods once succeeded in optimizing the biotransformation of glycyrrhizin [19]

In this study, PB and BBD experimental designs were used to optimize the parameters of fermentation forth of ginsenoside Re bioconversion to Rh1. The variables were screened, and the actual value of the important factors were estimated.

\section{Material and methods}

\subsection{Material}

\subsubsection{Microorganism}

Aspergillus tubingensis was isolated at The Department of Microorganism of the University of Science and Technology Liaoning and identified according to its morphology and rDNA gene sequence (KX664401.1) by Sangon Biotech (Shanghai) Co. Ltd.

\subsubsection{Media and cultivation}

Slope plate medium $(\mathrm{g} / \mathrm{L})$ : Potato juice, 200; glucose, 20.00; peptone, 10.00; agar, 20.00; $\mathrm{pH}$ 5.50; Seed culture $(\mathrm{g} / \mathrm{L})$ : Potato juice, 20.00; raw extraction of GL, 1.00 ; glucose, 10.00; peptone, 10.00; $\mathrm{pH} 5.50$; in a shaker for cultivation; Basal fermentation cultivation medium $(\mathrm{g} / \mathrm{L})$ : 98\% GL, 1.20; NaNO3, 1.50; K2HPO4, 1.00;

\footnotetext{
a Xiuhong Wu:wxh93@163.com
} 
All the media and cultivation were sterilized under the temperature of $121{ }^{\circ} \mathrm{C}$ and keep for 20 minutes

\subsection{Methods}

\subsubsection{Preparation of Aspergillus tubingensis seed culture}

Under the case of sterilization, an A. tubingensis spore suspension was prepared by washing spores from slope plates by sterile water. The suspension was inoculated for $72 \mathrm{~h}$ in a rotary shaker under the temperature of $28^{\circ} \mathrm{C}$ and the rate of $160 \mathrm{r} / \mathrm{min}$. Then seed cultivation medium was filtered with gauze and was washed for several times with sterile water until the prepared mycelia suspensions contained no ginsenoside Re. The seed culture was then used for further experiment.

\subsubsection{Preparation of fermentation culture}

$10 \mathrm{ml}$ seed medium was inoculated in the $100 \mathrm{ml}$ fermentation culture medium in a $250 \mathrm{ml}$ Erlenmeyer flask and then cultured in a rotary shaker at $28^{\circ} \mathrm{C}$ and 160 $\mathrm{r} / \mathrm{min}$ for $120 \mathrm{~h}$. Finally, the fermentation culture was centrifuged at $4000 \mathrm{r} / \mathrm{min}$ for $10 \mathrm{~min}$. Then the transformation yield was calculated with the following formula:

$$
A \%=\frac{C_{1} V_{1}}{C_{0} V_{0}} \times 100 \%
$$

Where $A$ is the transformation ratio, $C_{0}$ is the initial concentration of ginsenoside $\mathrm{Re}$ at the initial time of the fermentation, $\mathrm{mg} / \mathrm{L} ; \quad V_{0}$ is the initial volume of transformation forth, $\mathrm{mL} ; C_{1}$ is the concentration of ginsenoside transformed, $V_{1}$ is the final volume of fermentation forth. Ginsenoside Re, Rh1 were measured using Agilent 1100 HPLC (Agilent technology, USA) with Agilent Extend $\mathrm{C}_{18}(4.6 \mathrm{~mm} \times 250 \mathrm{~mm}, 5 \mu \mathrm{m})$. Chromatographic conditions for analysis as: mobile phase, acetonitrile: $\mathrm{H}_{2} \mathrm{O}=70: 30 \quad(\mathrm{v} / \mathrm{v})$; column temperature, $25.0{ }^{\circ} \mathrm{C}$; mobile phase rate, $1.00 \mathrm{ml} / \mathrm{min}$; wavelength, $203 \mathrm{~nm}$; UV detector.

\subsection{Experiment design}

\subsubsection{Steepest ascent design}

Plackett-Burman experiment design was first used to estimate the influence factors. And then steepest ascent design was used to approach the optimal range of each factor. Steepest ascent design takes the variation direction of the gradient as the ascent direction to make the process of optimization rapidly and economically

\subsubsection{Box-Benhnken design (BBD)}

BBD is a statistical method to solve multivariable problem. Compared with other general methods such as single-factor experimental and orthogonal design, BBD was characterized by its less experiment time, and a relative higher accurate regression equation [20-23].

\section{Result and discussion}

\subsection{Estimation of the main influence factors}

The software Design-Expert 8.0.6 experimental design was used in this work for designing PB experiment. According to the numbers of factors of the biotransformation system, experimental runs was set to $\mathrm{N}=12$. nine influential factors include: cultivation time (A), $C_{\mathrm{Re}}(\mathrm{B}), \mathrm{MgSO}_{4} \cdot 7 \mathrm{H}_{2} \mathrm{O}$ (D), $\mathrm{NaNO}_{3}(\mathrm{E}), \mathrm{K}_{2} \mathrm{HPO}_{4}(\mathrm{~F})$, peptone $(\mathrm{G})$, inoculation amount $(\mathrm{H})$, cultivation temperature(I), and $\mathrm{pH}(\mathrm{J})$ were investigated. Besides, $(\mathrm{C})$ and $(\mathrm{K})$ were two virtual variables to meet the running of the software. Each factor was considered by low level and high level, respectively. Bioconversion ratio was served as the response value, and the experiment was carried out duplicate. Detailed experiment design and the results of running were listed in Table 1.

Table 1. Plackett-Burman design and the corresponding response measurements variable (coded value) $(\mathrm{N}=12)$

\begin{tabular}{lllllllllllll}
\hline & $\mathbf{A}$ & $\mathbf{B}$ & $\mathbf{C}$ & $\mathbf{D}$ & $\mathbf{E}$ & $\mathbf{F}$ & $\mathbf{G}$ & $\mathbf{H}$ & $\mathbf{I}$ & $\mathbf{J}$ & $\mathbf{K}$ & $\mathbf{A} \%$ \\
\hline 1 & 1 & 1 & -1 & -1 & -1 & 1 & -1 & 1 & 1 & -1 & 1 & 14.4 \\
2 & 1 & -1 & 1 & 1 & -1 & 1 & 1 & 1 & -1 & -1 & -1 & 27.5 \\
3 & 1 & -1 & -1 & -1 & 1 & -1 & 1 & 1 & -1 & 1 & 1 & 19.5 \\
4 & -1 & 1 & -1 & 1 & 1 & -1 & 1 & 1 & 1 & -1 & -1 & 16.0 \\
5 & -1 & 1 & 1 & -1 & 1 & 1 & 1 & -1 & -1 & -1 & 1 & 16.8 \\
6 & 1 & 1 & 1 & -1 & 1 & -1 & 1 & -1 & 1 & 1 & -1 & 26.3 \\
7 & -1 & -1 & -1 & 1 & -1 & 1 & 1 & -1 & 1 & 1 & 1 & 37.2 \\
8 & 1 & 1 & -1 & 1 & -1 & 1 & -1 & -1 & -1 & 1 & -1 & 6.6 \\
9 & 1 & -1 & 1 & 1 & 1 & -1 & -1 & -1 & 1 & -1 & 1 & 22.4 \\
10 & -1 & 1 & 1 & 1 & 1 & -1 & -1 & 1 & -1 & 1 & 1 & 8.0 \\
11 & -1 & -1 & 1 & -1 & -1 & 1 & -1 & 1 & 1 & 1 & -1 & 32.9 \\
12 & -1 & -1 & -1 & -1 & 1 & -1 & -1 & -1 & -1 & -1 & -1 & 13.7 \\
\hline
\end{tabular}

The experimental results of $\mathrm{PB}$ was input to the software SPASS for statistical analysis. The effects of various factors on response variable are cultivate time (A), Re concentration (B) and $\mathrm{pH}(\mathrm{J})$. In Table 2, item B indicated the positive or negative of effect of the factor. Therefore, from Table 2, cultivation time (A) and $\mathrm{pH}(\mathrm{J})$ need increase, while Re concentration (B) may need decreased in the following experiment.

\subsection{Estimation optimal factor levels of by steepest ascent method Estimation optimal factor levels of by steepest ascent method}

Based on the results showed in Table 2. A steepest ascent experiment was designed, and the range of the influential factors was shown in Table 3. The other factors were maintained at their optimal levels. The results obtained were also shown in Table 3. 
Table 2. Regression coefficients and their significance level

\begin{tabular}{ccccc}
\hline Factor & $\begin{array}{c}\text { Effect } \\
\text { (B value) }\end{array}$ & $\begin{array}{c}\text { Standard } \\
\text { error }\end{array}$ & $\boldsymbol{t}$ ratio & $\boldsymbol{p}$-value \\
\hline Total & & 28.36 & 14.09 & 0.005 \\
A & 25.29 & 12.64 & 6.28 & 0.050 \\
B & -42.02 & -21.01 & -10.44 & 0.016 \\
D & 6.54 & 3.27 & 1.63 & 0.131 \\
D & -25.36 & -12.68 & -6.30 & 0.268 \\
E & -2.42 & -1.21 & -0.60 & 0.402 \\
F & -10.77 & -5.39 & -2.68 & 0.076 \\
H & 29.09 & 14.55 & 7.23 & 0.056 \\
I & 13.41 & 6.71 & 3.33 & 0.508 \\
J & 36.63 & 18.32 & 9.10 & 0.002 \\
\hline
\end{tabular}

*Significant at $\mathrm{p}<0.05$

Table 3. Steepest ascent design and the corresponding values

\begin{tabular}{ccccc}
\hline $\begin{array}{c}\text { Trial } \\
\text { number }\end{array}$ & $\begin{array}{c}\boldsymbol{C}_{\boldsymbol{R} e} \\
(\mathbf{m g} / \mathbf{L})\end{array}$ & $\mathbf{p H}$ & $\begin{array}{c}\text { Cultivate } \\
\text { time(days) }\end{array}$ & $\boldsymbol{A} \%$ \\
\hline 1 & 200 & 3.5 & 4 & 19.65 \\
2 & 500 & 4.0 & 5 & 17.92 \\
3 & 1000 & 5.0 & 6 & 22.32 \\
4 & 1500 & 7.0 & 7 & 11.89 \\
\hline
\end{tabular}

From Table 3, we can see that the highest biotransformation ratio was obtained in trial 3. Hence, the factor levels of this trial were used as the central point of response surface optimization in the subsequent BBD experiment.

\subsection{Estimation of optimal levels of the main factors by Box-Benhnken Design}

The results of the steepest ascent design were used for further optimization in BBD to estimate factors and levels. Three influence factors i.e. cultivation time, $\mathrm{pH}$ and concentration of Re with three level's response surface analysis experiment were carried out. Two types of experimental data points were selected: the factorial point and the zero point which was the central point of the investigation range. The results of seventeen trials are shown in Table 4.

\subsection{Analysis experiment data of BBD}

The biotransformation ratio was served as the response variable. Multi-variable regression analysis was carried out using the software Design-Expert 8.0.6. The analysis results are shown in Table 5. After regression and fitting, a quadratic regression polynomial was obtained. The response value verse variables $\mathrm{A}, \mathrm{B}$ and $\mathrm{C}$ in term of code is as followed:

$A \%=48.24+4.51 \mathrm{~A}-7.77 \mathrm{~B}-4.58 \mathrm{C}-8.85 \mathrm{AB}+5.02 \mathrm{AC}-$

$2.40 \mathrm{BC}-8.82 \mathrm{~A}^{2}-13.73 \mathrm{~B}^{2}-3.12 \mathrm{C}^{2}$

Where $\mathrm{A}$ was the dependent variable, the arithmetic mean response of the 17 runs was 48,24 , and the estimated coefficients for factors $\mathrm{A}, \mathrm{B}$, and $\mathrm{C}$ were 4.51, -7.77 and -8.85 , respectively. The main effects (A and B) represented the average result of changing one factor at a time from low to high value. The interactive terms (AB. $\mathrm{BC}$, and $\mathrm{AC}$ ) showed how the response changes when three factors were simultaneously changed. The polynomial terms $\left(\mathrm{A}^{2}, \mathrm{~B}^{2}\right.$, and $\left.\mathrm{C}^{2}\right)$ were included to investigate nonlinearity. The regression model needed to be evaluated for model significance and the lack-of-fit. Analysis of variance (ANOVA) was used for these evaluations.

Table 4. Box-Benhnken experimental design conditions and the corresponding values

\begin{tabular}{ccccc}
\hline $\begin{array}{c}\text { Trial } \\
\text { numbe } \\
\text { r }\end{array}$ & $\begin{array}{c}\text { A: } \\
\text { Cultivatio } \\
\text { n time }\end{array}$ & B: $\mathbf{p H}$ & $\begin{array}{c}\mathbf{C}: \\
\text { Ginsenoside } \\
\text { Re }\end{array}$ & $\boldsymbol{A} \%$ \\
\hline 1 & 0 & 0 & 0 & 39.6 \\
2 & 1 & 0 & -1 & 38.6 \\
3 & -1 & 0 & 1 & 24.0 \\
4 & -1 & 1 & 0 & 21.6 \\
5 & 0 & 0 & 0 & 53.6 \\
6 & -1 & -1 & 0 & 17.7 \\
7 & 0 & -1 & 1 & 37.6 \\
8 & 0 & 0 & 0 & 49.5 \\
9 & 1 & 0 & 1 & 39.9 \\
10 & 0 & -1 & -1 & 42.4 \\
11 & 1 & -1 & 0 & 47.5 \\
12 & 0 & 0 & 0 & 48.7 \\
13 & 1 & 1 & 0 & 16.0 \\
14 & 0 & 0 & 0 & 49.8 \\
15 & 0 & 1 & 1 & 15.5 \\
16 & -1 & 0 & -1 & 42.7 \\
17 & 0 & 1 & -1 & 30.0 \\
\hline
\end{tabular}

Table 5. ANOVA for BB Design quadratic model

\begin{tabular}{lllllll}
\hline Source & $\begin{array}{l}\text { Sum of } \\
\text { Square }\end{array}$ & DF & $\begin{array}{l}\text { Mean } \\
\text { Square }\end{array}$ & $\begin{array}{c}\text { F } \\
\text { Value }\end{array}$ & $\begin{array}{c}\text { P } \\
\text { Value }\end{array}$ & Significance \\
\hline Model & 2509.81 & 9 & & 14.60 & 0.0009 & significant \\
A & 162.72 & 1 & & 8.52 & 0.0224 & \\
B & 482.52 & 1 & & 25.26 & 0.0015 & \\
C & 167.72 & 1 & & 8.78 & 0.0210 & \\
AB & 313.29 & 1 & & 16.40 & 0.0049 & \\
AC & 100.80 & 1 & & 5.28 & 0.0552 & \\
BC & 22.99 & 1 & & 1.20 & 0.3089 & \\
A $^{2}$ & 327.90 & 1 & & 17.17 & 0.0043 & \\
$B^{2}$ & 794.00 & 1 & & 41.57 & 0.0004 & \\
C $^{2}$ & 40.91 & 1 & & 2.14 & 0.1867 & \\
Residual & 133.69 & 7 & 19.10 & & & not \\
Lack of & & & & & & \\
Fit & 25.97 & 3 & 8.66 & 0.32 & 0.8109 & significant \\
Pure Error & 107.72 & 4 & 26.93 & & & \\
Cor Total & 2463.51 & 16 & & & & \\
R- & & & AdjR- & & & \\
Squared & & & Squared & & & \\
0.9494 & & & 0.8844 & & & \\
\hline
\end{tabular}

As shown in Table 5, both linear and quadratic terms of the equation were significant, indicating a nonlinear relationship between the influence variables and biotransformation ratio. The coefficient of the regression equation is $R^{2}=0.9494$ which means that the model may use for fitting the experimental data. The adjusted $R^{2}$ indicates that the three influence factors identified in the PB experiment explained $88.44 \%$ of the variance in the response variable. In addition, the lack of fit $\mathrm{P}>\mathrm{F}$ was 0.8109 ; therefore, the model has a practical significance [20-21].

According to the regression equation and the analysis summarized in Table 5, fitted surfaces of each pairs of factors in the reaction analysis can be derived; the threedimensional plots of interactions are shown in Figure 1(a)-(c). 


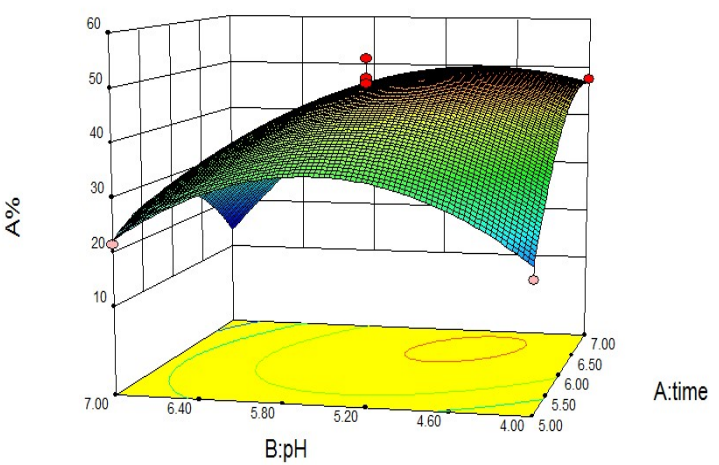

(a)

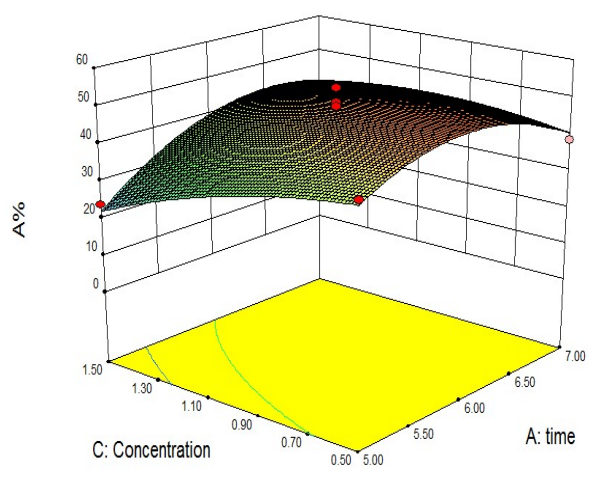

(b)

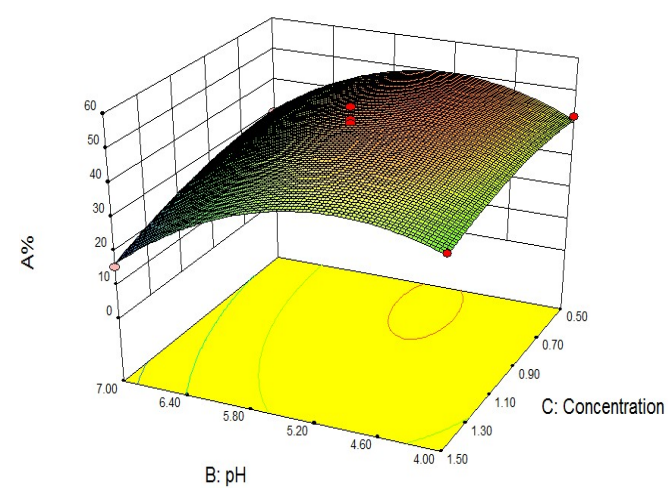

(c)

Figure 1. Fitted surface for the transformation ratio as a function of cultivation time (A) and $\mathrm{pH}(\mathrm{B})$ in (a), cultivate time (A) and ginsenoside $\mathrm{Re}(\mathrm{C})$ in (b) and $\mathrm{pH}(\mathrm{B})$ and ginsenoside $(\mathrm{C})$ in $(\mathrm{c})$

Figure 1. (a)-(c) showed that the influence between two factors presented a relationship of parabolic curve. Figure 1(a) showed that the percent biotransformation more significantly than time. The optimum $\mathrm{pH}$ was located between 2.0 and 4.0. As can be seen from Figure (b) and (c), pH and time affected the percent biotransformation more significantly than $\mathrm{Re}$ concentration. There is a maximum point in these three figures. The optimization results of $\mathrm{BBD}$ derived from the regression equation is $\mathrm{Re} 1.0 \mathrm{~g} / \mathrm{L}, \mathrm{pH} 4.5$ and cultivate time 7 days.

\subsection{Verification test}

To verify the accusation of the model established, the biotransformation of Re was carried out duplicate under the optimized condition i.e. Re $1.0 \mathrm{~g} / \mathrm{L}$, cultivation time 7 days and $\mathrm{pH}$ 4.50. The average percent transformation got reach to $51.76 \%$, a satisfied result for acquiring ginseenoside Rh1.

\section{Conclusion}

In this study, based on basal fermentation medium, PB design method was applied to estimate the most important influence factors among nine which may affect biotransformation ratio of $\mathrm{Re}$ to $\mathrm{Rh} 1$. The results showed that $\mathrm{Re}, \mathrm{pH}$ and cultivate time were the most obviously influence factors. To search the central point of the response surface experiment in a reasonable and simply way, steepest ascent experiment was used. The optimum fermentation conditions achieved by BBD are: Re 1.0 $\mathrm{g} / \mathrm{L}, \mathrm{NaNO}_{3} 3.0 \mathrm{~g} / \mathrm{L}, \mathrm{MgSO}_{4} \cdot 7 \mathrm{H}_{2} \mathrm{O} 1.5 \mathrm{~g} / \mathrm{L}, \mathrm{K}_{2} \mathrm{HPO}_{4} 3.0$ $\mathrm{g} / \mathrm{L}$, peptone $2.0 \mathrm{~g} / \mathrm{L}, \mathrm{pH} 4.50$, inoculums size $30.0 \mathrm{~mL}$, temperature $28.0{ }^{\circ} \mathrm{C}$ and cultivate time 7 days. $51.76 \%$ transformation ratio obtained based on above conditions.

\section{References}

1. L. W. Qi, C. Z. Wang, C. S. Yuan. Phytochemistry, 72 (2011), 689.

2. H. W. Park, G. In, S. T. Han, M.W. Lee, S.Y. Kim, K.T. Kim, B.G. Cho, G.H. Han, and I.M. Chang. J. Ginseng. Res., 37(4) (2013), 457.

3. A. Dey, R. Bhattacharya, A. Mukherjee, D. K. Pandey. Biotechnol. Adv. ,35 (2017), 178.

4. Z. P. Li, G. E. Ji. Food. Sci. Biotechnol., 26(4) (2017), 987.

5. K. H. Chang, M. N. Jo, K.T. Kim, H.D. Paik. J. Ginseng. Res., 38 (2014), 47.

6. G.T. Chen, M. Yang., Z. Q. Lu, J.Q. Zhang, H. L. Huang, Y. Liang, S.H. Guan, Y. Song, L.J. Wu, and D.A. Guo. J. Nat. Prod., 70(2007), 1203.

7. S.R. Ko, K.J. Choi, K. Uchida, Y. Suzuki.. Plata. Med., 69(2003), 285.

8. L.H. Quan, C. Wang, Y. Jin, T. R. Wang, Y. J. Kim, D. C. Yang. Antonie van Leeuwenhoek, 104 (2013),129.

9. J. Upadhyaya, M.J. Kim, Y. H. Kim, S.R. Ko, H.W. Park, M.K. Kim. J. Ginseng. Res., 40 (2016), 105.

10. L.P. Wu, Y. Jin, C.R. Yin, L.L. Bai. J. Ind. Microbiol. Biotechnol., 39 (2012), 521.

11. Gao, W.J. Xu, Q. Fang, F. Liang, R.T. Jin, D. Wu, G.H. Tai and Y.F. Zhou.. Ann. Microbiol., 63 (2013),139. 12. G.W. Lee, K. R. Kim, D. K. Oh. Biotechnol. Lett., 34 (2012), 1679.

13. S.A. Palaniyandi, B. M. Son, K. Damodharan, J.W Suh, and S. H. Yang. Biotechnol. Biopro. E., 21(2016), 587.

14. P. F. Yue, Q. Zheng, B. Wu, P.Y. Hu, Z. F. Wu and M. Yang. J. Disper. Sci. Technol., 33(2) (2012), 213.

15. B. Gullóan, G. Garrote, J. L. Alonso, and J.C. Parajó. J. Agric. Food. Chem., 55(2007), 5580. 
16. H. S. Oberoi, P. V. Vadlani, R. L. Madl, L. Saida, and J.P. Abeykoon. J. Agric. Food. Chem., 58(2010), 3422

17. S. Chatterjee, A. Kumar, S. Basu, S. Dutta. Chem. Eng. J., 181-182 (2012), 289.

18. S.S. Lin, W.F. Dou, H.Y. Xu, H. Z. Li, Z.H. Xu and Y.H. Ma. Appl Microbiol Biotechnol., 75 (2007),1015

19. Y. L. Quan, L. Wang, Y. S. Liu, J.X. Cong, S.Q Xie, and X.H. Wu. Korean Chem. Eng. Res., 53(3) (2015), 321.

20. Namita Gupta, Gauri Mehra, and Rani Gupta. Can. J. Microbiol., 50(5) (2004), 361.

21. S. Ali and I. Haq. BMC Biotechnol., 10 (2010), 86

22. J.N. Hu, J.H. L. X.M. Zhu, J.A. Shin, P. Adhikari, J.K. Kim, and K.T. Lee. J. Agric. Food. Chem., 56(2008), 10988.

23. T. Palvannan and P. Sathishkumar, J. Basic. Microb., 50(2010), 325. 